\title{
Explanation of the Compensation Law and the Isokinetic Point in the Electrical Conduction of Crosslinked Polyethylene
}

\author{
Roger Walker $\mathbb{D},{ }^{1}$ Eugene Furman $\mathbb{D}^{2},{ }^{2}$ William H. Hunter Woodward $\mathbb{D}^{3}$ \\ and Michael Lanagan ${ }^{1}{ }^{1}$ \\ ${ }^{1}$ The Pennsylvania State University, Department of Materials Science and Engineering, University Park, PA 16802, USA \\ ${ }^{2}$ The Pennsylvania State University, Materials Research Institute, University Park, PA 16802, USA \\ ${ }^{3}$ The Dow Chemical Company, Analytical Sciences, Core R\&D, Midland, MI 48667, USA
}

Correspondence should be addressed to Roger Walker; rcw202@psu.edu

Received 6 August 2021; Revised 7 December 2021; Accepted 18 January 2022; Published 7 February 2022

Academic Editor: Qinglin Wu

Copyright (c) 2022 Roger Walker et al. This is an open access article distributed under the Creative Commons Attribution License, which permits unrestricted use, distribution, and reproduction in any medium, provided the original work is properly cited.

\begin{abstract}
Thermally activated direct current (DC) electrical conductivity in low-density polyethylene (LDPE) is known to be subject to the compensation law. Accordingly, the preexponential factor follows a specific relation with activation energy, reducing overall changes in conductivity. This relationship is governed by the Meyer-Neldel temperature. However, there is no published evidence for a corresponding isokinetic point, a temperature where the conductivity of all LDPE samples is the same. Here, it is determined that the compensation law applies to both DC and alternating current (AC) conduction for LDPE and for crosslinked polyethylene (XLPE) without an observed isokinetic point. The potential origins of compensation in polyethylene are discussed as well as reasons for similarity between LDPE and XLPE. It is observed that prolonged water exposure removed the compensation behavior. Meanwhile, preheating samples in the oven prior to measurements modifies the compensation behavior and reduced the spread around the isokinetic point. It is thus deduced that an isokinetic point can be observed in polyethylene but is obscured by contributions from water and other impurities.
\end{abstract}

\section{Introduction}

Electrical conduction in many polymeric insulators, such as polyethylene, is a thermally activated process. The conductivity under moderate electrical fields where Ohm's law applies, $\sigma$, is governed by the Arrhenius equation:

$$
\sigma=\sigma_{0} \exp \left(-\frac{E_{A}}{k_{B} T}\right)
$$

where $k_{B}$ is Boltzmann's constant, and $T$ is the absolute temperature. Usually, the activation energy $E_{A}$ and the preexponential term $\sigma_{0}$ are constants for a specific material. However, for many materials including ionic conductors, electronic semiconductors, and polymers, it has been observed that within a family of related materials, or for the same material processed under varying conditions, $E_{A}$ is not constant and is instead related to $\sigma_{0}$. This observation is the "compensation law" [1], called as such because the change in $\sigma_{0}$ partially compensates for the change in $E_{A}$, leading to similar conductivity values between samples at certain temperatures. It can be written as the following:

$$
\sigma_{0}=\sigma_{00} \exp \left(\frac{E_{A}}{E_{\mathrm{MNR}}}\right)
$$

Here, $\sigma_{00}$ is another preexponential term, and $E_{\mathrm{MNR}}$ is the "Meyer-Neldel energy." $E_{\mathrm{MNR}}$ can also be expressed as $k_{B} T_{\mathrm{MNR}}$. At $T_{\mathrm{MNR}}$, the conductivity takes on a fixed value independent of the activation energies of related samples, due to strict compensation by the preexponential factor. The isokinetic relationship is the existence of $T_{\mathrm{MNR}}$, which is referred to as an "isokinetic temperature" or "isokinetic 
point" in the literature. The isokinetic point, which is the term that will be used for the rest of this paper, can be presented via a plot of conductivity vs. temperature of all samples analyzed and ideally should correspond to the value that was extracted using Equation (2).

In much of the literature, the Meyer-Neldel law and the compensation law are used interchangeably for materials subject to Equation (2). In chemistry, the equivalent rule is referred to as isokinetic rule [2]. In this paper, the compensation law is a general description specifying a positive correlation of $\ln \sigma_{0}$ and $E_{A}$, while the isokinetic relationship is a stricter requirement of a common conductivity at a characteristic isokinetic temperature. Several examples exist of materials that exhibit both compensation and isokinetic temperature, such as plasma polythiophene [3] and siliconesilver nanocomposites [4]. When both are present, then conventional models such as multiexcitation entropy can be used to explain these results $[5,6]$.

However, evidence has emerged over the years that the compensation law and the isokinetic relationship are distinct. If this is the case, then it should be possible to analyze samples exhibiting compensation alone, and multiple examples can be found in the literature [7-10]. Two examples cover hypothetical data $[7,8]$ while the others are based on measured data $[9,10]$. These papers make it clear that while an isokinetic point is implied by the presence of compensation, it is not certain to exist. Particularly, it was noted that deviations from the isokinetic point, even large ones, will only have a small impact on the compensation plot. This is because compensation is determined using a best fit line, which can accommodate deviations, while an isokinetic relationship is determined by a common point of intersection, which cannot. This is demonstrated in Figure S1, where two sets of schematic conductivity data were generated. One shows an isokinetic point, and the other does not, but both show compensation with excellent fit. A plot of conduction against temperature (as the relevant parameters in this work) where the isokinetic point is present is strictly necessary to prove that it exists. Thus, only if both are clearly shown should that material be considered to obey the "Meyer-Neldel rule"; otherwise, only compensation should be claimed.

In low-density polyethylene (LDPE), compensation has been observed as early as the 1970s in studies analyzing conduction mechanisms in polyethylene [11, 12]. Thermally activated conduction for LDPE generally can be observed at $50^{\circ} \mathrm{C}$ and above. An analysis of LDPE prepared and measured under different conditions revealed compensation behavior with parameters of $T_{\mathrm{MNR}}=97^{\circ} \mathrm{C}$ and $\sigma_{00}=3.4 \times$ $10^{-14} \mathrm{~S} \mathrm{~m}^{-1}$, similar to organic semiconductors [11]. An investigation of uniaxially drawn LDPE found similar parameters $\left(T_{\mathrm{MNR}}=87^{\circ} \mathrm{C}\right.$ and $\left.\sigma_{00}=1.72 \times 10^{-14} \mathrm{~S} \mathrm{~m}^{-1}\right)$ [12]. In all cases, however, no explicit isokinetic points were shown.

Investigations of electrical compensation and isokinetic behavior in polyethylene variants are lacking. In particular, an investigation of crosslinked polyethylene (XLPE) is relevant given its use as power cable insulation [13]. XLPE is commonly made by connecting LDPE branches together in a three-dimensional network using a crosslinking agent.
Commercial XLPE is crosslinked using dicumyl peroxide (DCP) and is degassed to remove DCP byproducts [14], making it as or less conductive than LDPE [15, 16]. XLPE conductivity is also thermally activated. A better understanding of the mechanisms controlling electrical conductivity with respect to temperature and experimental conditions is of great interest to the power transport community. Reduced conductivity allows for operation at higher voltages, and increasing voltage by a factor of ten reduces transmission losses by a factor of one hundred for the same power level. Transmission and distribution losses are approximately $6 \%$ of the electricity generated in the United States [17]. Reducing this value to $5 \%$ would reduce annual $\mathrm{CO}_{2}$ emissions by 19.3 million metric tons based on 2016 estimates from the U.S. Energy Information Administration. There is thus great value in better understanding and controlling electrical conduction in XLPE.

This study shows that, like LDPE, XLPE exhibits the compensation law, which addresses the variations in insulation performance. Neither of the two polymers exhibited a clear isokinetic point for either AC or DC conduction. Water content was found to be a major factor in determining the overall conductivity and if compensation is present. The ambient environment and volatile molecules also played a critical role in determining if the isokinetic point would be observed, as well as the conductivity and compensation behavior.

\section{Experimental Procedure}

2.1. Material Processing. LDPE was obtained from Dow (density of $0.923 \mathrm{~g} \mathrm{~cm}^{-3}$, melt mass flow rate of $1.8 \mathrm{~g}$ per 10 minutes of $2.16 \mathrm{~kg}$ at $463 \mathrm{~K})$. DCP (98\% pure) was obtained from Sigma-Aldrich. To create XLPE, 2.1-10 wt\% DCP was soaked into LDPE in an oven at $55^{\circ} \mathrm{C}$. LDPE and XLPE films were created by melt pressing neat and DCP-infused polyethylene beads, respectively, at temperatures above the melting point. A uniaxial pressure of $17.24 \mathrm{MPa}(2500 \mathrm{psi})$ was applied to compress the molten polymer, and the pressure was continuously applied for 12 minutes. The temperature was $180^{\circ} \mathrm{C}$ for all LDPE samples but was varied slightly for XLPE samples to examine the crosslinking step as a variable. Samples were air cooled to room temperature while maintaining pressure. Obtained film thicknesses were in the range of 100-300 $\mu \mathrm{m}$. Samples were degassed in a vacuum oven at $65^{\circ} \mathrm{C}$ for 72 hours. After degassing, $50 \mathrm{~nm}$ aluminum electrodes were applied using an electron beam evaporator at a nominal deposition rate of $2.5 \AA^{-1}$.

2.2. Electrical Characterization. DC and AC electrical measurements were carried out using conduction current measurements (CCM) and broadband dielectric spectroscopy (BDS), respectively. CCM was done by applying a $2000 \mathrm{~V}$ bias across the film and measuring the current at evenly spaced temperatures in a range from $25^{\circ} \mathrm{C}$ to $90^{\circ} \mathrm{C}$. The current was measured for 1000 seconds, and the average value of the current obtained from 500 to 1000 seconds was taken as representative for each temperature and used to compute values for $\sigma$. BDS was done by applying a $1 \mathrm{~V}$ rms AC bias 
across the film and measuring the capacitance and dielectric loss as a function of temperature utilizing $10 \mathrm{~K}$ steps. These values were measured in a frequency range from $0.1 \mathrm{~Hz}$ to $100 \mathrm{kHz}$. After converting the dielectric loss to conductivity, a roughly constant conductivity values were observed for frequencies between 0.1 and $10 \mathrm{~Hz}$ at elevated temperatures. As such, the conductivity values at $0.1,1$, and $10 \mathrm{~Hz}$ were used when fitting the data to Equation (1). Once conductivity values for both DC and AC were obtained, the activation energy and preexponential factor were obtained using Equation (1). After the activation energy and preexponential factor were obtained from multiple samples of the same type, the Meyer-Neldel energy was determined using Equation (2). $T_{\text {MNR }}$ was also obtained using Equation (2) and indicated on plots of conductivity vs. temperature to determine if an isokinetic point was present or not. If both $\mathrm{DC}$ and $\mathrm{AC}$ measurements were done on a sample, the AC measurements were always done first.

\section{Experimental Results}

3.1. DC Conductivity of XLPE and LDPE. Discussed here are the results of an analysis of the variable activation energy and preexponential factor in XLPE and LDPE. Two groups of XLPE samples with constant processing parameters were prepared (2.14\% DCP and 2.3\% DCP, both with crosslinking temperatures of $180^{\circ} \mathrm{C}$ ), while additional samples were prepared with variable initial DCP concentrations and variable crosslinking temperatures to determine how those factors impact conductivity and the activation energy. The resulting best fit lines of conductivity vs. temperature for all these XLPE samples are presented in Figure 1. Figure 2 contains the conductivity vs. temperature best fit lines for a control set of LDPE samples, prepared for comparative purposes. For both, the compensation law plots are provided for a side-by-side comparison, and they indicate that compensation is present. For both XLPE and LDPE, good linear fits were obtained from the plot of $E_{A}$ vs. $\ln \sigma_{0}$ with $R^{2}$ values of 0.967 and 0.939 , respectively (compensation plots are examined in more detail in 3.2).

Raw DC conductivity values were similar for XLPE and LDPE and tended to range from $10^{-15}$ to $10^{-13} \mathrm{~S} \mathrm{~m}^{-1}$. These values are comparable to what has been seen in the literature [15]. This means that correlations cannot be made between physical parameters like crystallinity and the conductivity. The average crystallinity for XLPE $(\approx 30 \%)$ and for LDPE $(\approx 40 \%)$ differ due to the crosslinks disrupting the crystallization process, with no apparent impact on the measured conductivity. This is in line with the results found in polyethylene [11] and other polymers [3]. Similarly, there was sufficient variation in the conductivity in the XLPE samples prepared with $2.14 \%$ and $2.3 \%$ DCP such that altering the $\% \mathrm{DCP}$ or the crosslinking temperature could not be correlated with any specific impact.

The isokinetic points are indicated on the two conductivity plots $\left(53^{\circ} \mathrm{C}\right.$ for XLPE and $58^{\circ} \mathrm{C}$ for LDPE), where it can clearly be seen that an isokinetic point is absent for XLPE or LDPE. It is noted, however, that a subset of the XLPE samples appears to exihibit isokinetic behavior, which has been seen in other situations [10]. This is an apparent effect, due to the spread in the data, with no physical meaning. Similar compensation parameters in LDPE and XLPE exclude the possibility that conductivity is controlled by impurities unique to one of the two materials, in particular, the residual byproducts of crosslinking in XLPE.

The presence of compensation without a clear isokinetic point motivated the search for an explanation. First, measurement and/or experimental error should be ruled out $[7,18,19]$. Such errors are reported to lead to an apparent isokinetic effect $[18,19]$ and a much narrower range of activation energies than observed in LDPE and XLPE [20]. Additionally, said apparent isokinetic point would match that of the lowest temperature used in measurement, which for this experiment is room temperature [7]. Neither situation was observed here. As such, a cause of the large variations in activation energy and preexponential term should be sought out.

3.2. Activation Energy of XLPE and LDPE. A compensation plot that compares the DC conductivity parameters-activation energy and preexponential factor-from the measured XLPE and LDPE samples to the results obtained by Sawa et al. is shown in Figure 3 [11]. There is significant overlap between XLPE and LDPE in terms of activation energy and preexponential values. Values of $E_{A}$ range from $0.15 \mathrm{eV}$ to $0.85 \mathrm{eV}$ for XLPE and $0.2 \mathrm{eV}$ to $0.8 \mathrm{eV}$ for LDPE. The XLPE samples prepared with $2.14 \%$ DCP had significant variance in $E_{A}$, having values of $0.21 \mathrm{eV}, 0.43 \mathrm{eV}$, and $0.65 \mathrm{eV}$. The XLPE samples prepared with $2.3 \% \mathrm{DCP}$, on the other hand, had values around $0.67 \mathrm{eV}$ for all but one, which had an $E_{A}$ value of $0.83 \mathrm{eV}$. No correlations could be made between either initial DCP concentration or crosslinking temperature and the resulting activation energy. However, each of these subsets of XLPE samples also exhibited compensation without a corresponding isokinetic point.

There was a clear difference in the obtained isokinetic point between our samples $\left(53^{\circ} \mathrm{C}\right.$ for XLPE and $58^{\circ} \mathrm{C}$ for LDPE), the Sawa literature reference $\left(97^{\circ} \mathrm{C}\right.$ for LDPE), and the previously mentioned examples. The data shown in Sawa et al. were combined from several reports of thermally activated conduction in LDPE. There, the values of activation energy ranged from $0.35 \mathrm{eV}$ to $1.5 \mathrm{eV}$, and some samples do match up with the $E_{A}$ and $\ln \sigma_{0}$ values obtained in these experiments. Sawa reported an absence of any apparent correlation between the processing parameters used to make samples and their Arrhenius parameters on the compensation law plot. The same is true in the present case, as discussed in the prior subsection.

Sawa found that holding the applied DC voltage for a longer time in isothermal current measurements led to monotonic increases in both $E_{A}$ and $\sigma_{0}$, and thus compensation could be observed in a single sample by varying experimental conditions for the conductivity measurements. However, we also found examples of monotonic decreases in both parameters, in addition to examples of the monotonic increases. Figure 4 shows compensation observed in two representative LDPE and XLPE samples cut from identically processed films. The two samples exhibit opposite 


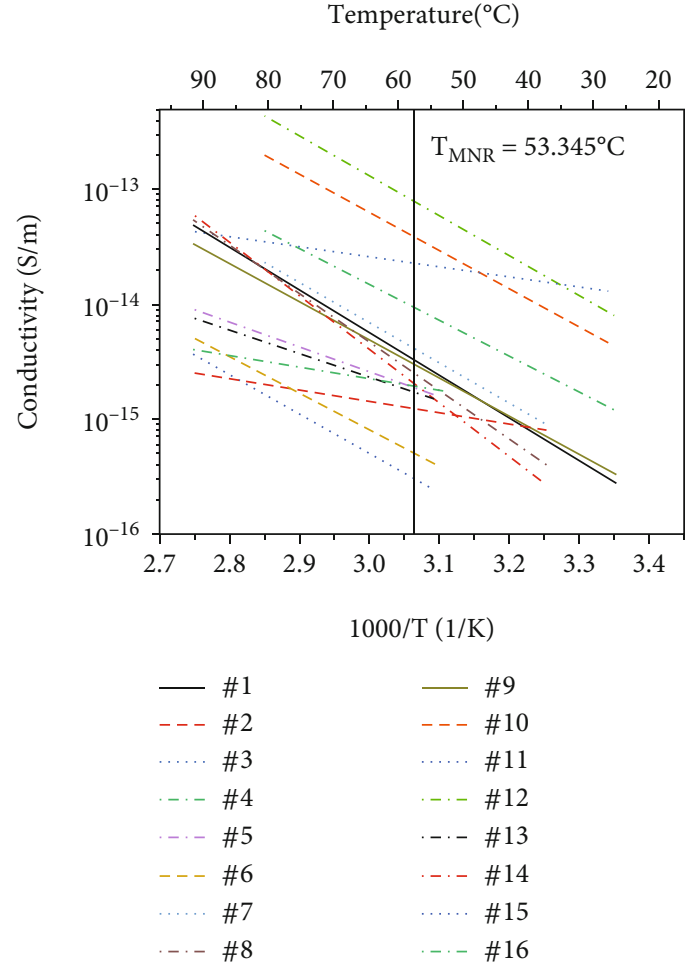

(a)

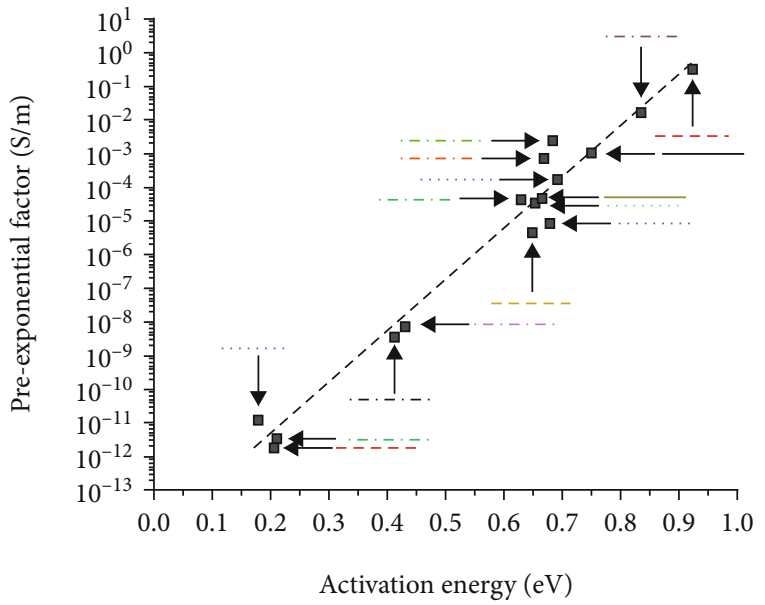

- Degassed XLPE-CCM

- - Best fit line

(b)

FIgure 1: (a) Conductivity vs. temperature plot and (b) compensation law plot for degassed XLPE samples. Crosslinking was achieved via melt pressing at a specific temperature (TXL) with a specific concentration of DCP for 12 minutes. All samples were degassed in a vacuum oven at $65^{\circ} \mathrm{C}$ for 72 hours. Sample parameters are as follows: $\# 1-2.12 \% \mathrm{DCP}, \mathrm{TXL}=160^{\circ} \mathrm{C}$; \#2-2.12\% DCP, TXL $=140^{\circ} \mathrm{C}$; \#3-2.12\% DCP, $\mathrm{TXL}=120^{\circ} \mathrm{C}$; $\#$ to $\# 6-2.14 \% \mathrm{DCP}, \mathrm{TXL}=180^{\circ} \mathrm{C}$; 7 to $\# 12-2.3 \% \mathrm{DCP}, \mathrm{TXL}=180^{\circ} \mathrm{C} ; \# 13-3.2 \% \mathrm{DCP}, \mathrm{TXL}=180^{\circ} \mathrm{C} ; \# 14-4.9 \% \mathrm{DCP}, \mathrm{TXL}=$ $180^{\circ} \mathrm{C}$; $\# 15-6.7 \% \mathrm{DCP}, \mathrm{TXL}=180^{\circ} \mathrm{C}$; and $\# 16-10 \% \mathrm{DCP}, \mathrm{TXL}=180^{\circ} \mathrm{C}$.

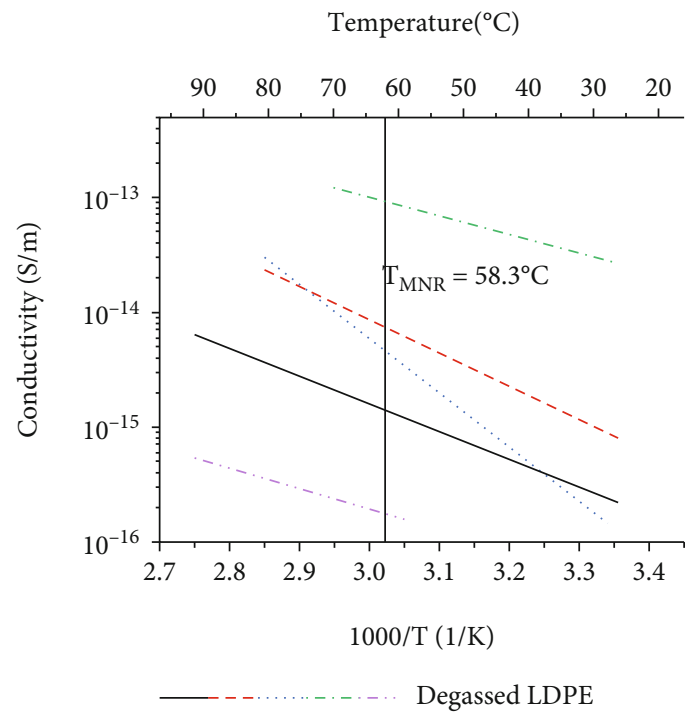

(a)

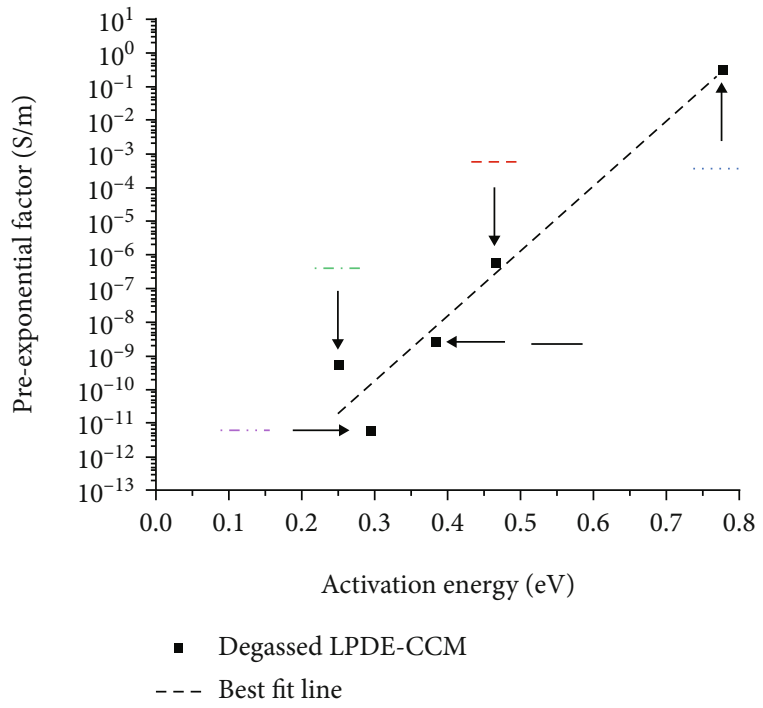

(b)

FIgure 2: (a) Conductivity vs. temperature plot and (b) compensation law plot for degassed LDPE samples. All samples melt pressed at $180^{\circ} \mathrm{C}$ for 12 minutes. Degassing done in a vacuum oven at $65^{\circ} \mathrm{C}$ for 72 hours. 


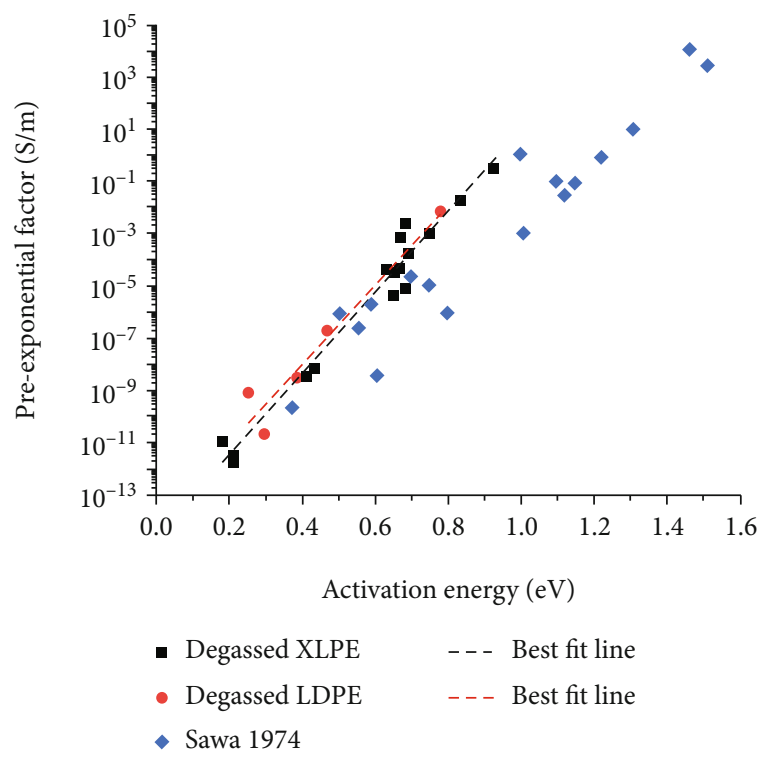

FIgURE 3: Compensation plot comparing degassed XLPE and degassed LDPE. Comparison LDPE data from the work of Sawa et al. is indicated separately.

behaviors. This implies that the activation energies in LDPE and XLPE may have more than one physical mechanism that contributes to the overall compensation behavior. Dispersive transport is well suited for explaining increasing activation energy with time, where progressively deeper traps dominate conduction over transport duration leading to increasing activation energy $[21,22]$. A reduction in activation energy with time can be accounted by the transport of water molecules into the regions of high electric field via dielectrophoresis. As water is more polarizable than the matrix, it is driven into the regions of high electric field and regions with dipolar defects which often act as deep traps, resulting in lowering of activation energy because of a time dependent increase in the polarizability of hydrated regions. When polyethylene is at a temperature lower than the isokinetic point, the most insulating regions are the ones with the highest activation energy for conduction. Consequently, water penetration into such regions can have strong influence on the effective activation energy. It can be conjectured that the key difference between these samples was the degree to which water had access to the most insulating regions.

3.3. Comparison of DC and AC Response. AC conduction was also investigated to determine if compensation with no apparent isokinetic point could be observed. The results are shown in Figure 5. All XLPE samples had the same initial DCP concentration and crosslinking temperature. The compensation law plots are presented in Figure 5(a) for XLPE and 5(b) for LDPE, along with comparisons to the DC data. Figures 5(c) and 5(d) are the corresponding plots of AC conductivity versus temperature for all the samples used to make the compensation plots, with the frequencies used during measurement labeled in the legend.

The compensation parameters for both $\mathrm{AC}$ and DC are shown in the compensation plots, with $T_{\mathrm{MNR}}$ being shown in the plots of conductivity versus temperature. Again, there was compensation between the activation energy and preexponential factor without a true isokinetic point. Instead, there was clustering to similar but not equivalent values near $T_{\mathrm{MNR}}$. While small differences between $E_{\mathrm{MNR}}$ were observed, the main difference was in the value of $\sigma_{00}$, which was about two to three orders of magnitude larger for AC data than for DC data.

Comparing the raw conductivity values between $\mathrm{DC}$ and AC analysis of XLPE and LDPE samples using Figures 1-3 reveals that DC conductivity values are universally lower by two to three orders of magnitude compared to the AC values. Additionally, conductivity values are comparable between LDPE and XLPE when both are degassed and measurements are done using CCM, while XLPE is slightly less conductive than LDPE under AC conditions.

One way to account for the difference between DC and $\mathrm{AC}$ conduction is to postulate that $\mathrm{AC}$ conduction is determined primarily by the average bulk properties in the polyethylene while DC conduction is more percolative. Percolation represents the extremes of the relevant material characteristics, which can account for the wide distribution of activation energies and apparent independence of sample preparation. Since AC conduction is several orders of magnitude greater than DC conduction, it supports the idea that it is governed much more by the average relevant properties of the polymer. Percolation still plays a role in AC conduction based on the observed spread in the measured activation energies, but it is more dominant in DC conditions.

Table 1 compares the compensation parameters of XLPE and LDPE from this work to literature sources which are limited to DC conduction. Compensation is observed statistically; so, a confidence interval was provided for both the energy and the temperature. Narrower confidence intervals were obtained using BDS due to the larger data set. Also notable is that the confidence intervals of LDPE and XLPE for $E_{\mathrm{MNR}}$ have significant overlap in DC analysis ( $p$ value = 0.923 ) but insignificant overlap in AC analysis ( $p$ value $=$ $0.008)$. The difference in AC is only $2 \mathrm{meV}(\sim 19 \mathrm{~K})$, however, and so is not practically very large. The similarity between XLPE and LDPE in CCM suggests that adding crosslinks does not change the conduction mechanisms for polyethylene in DC conditions. The same cannot be said for AC conditions based on the existing data, but it could not be determined if this statistically significant difference had any practical implications.

In any case, the physical cause of the variable activation energy had yet to be determined. It must be present in both $\mathrm{AC}$ and DC conduction and in both XLPE and LDPE. For these polyethylene variants, two main possibilities exist based on their composite structure. These two materials consist of multiple phases (amorphous, crystalline, and interface) and contain trace levels of various impurities (DCP byproducts, water, oxygen, etc.). All the XLPE samples are fully degassed thin films; so, the DCP byproducts would play a reduced role, and they are absent from LDPE. This leaves other impurities such as water and oxygen as the possible culprits. These impurities have varying trap depths in polyethylene [24]; so, variance in the most common trap 


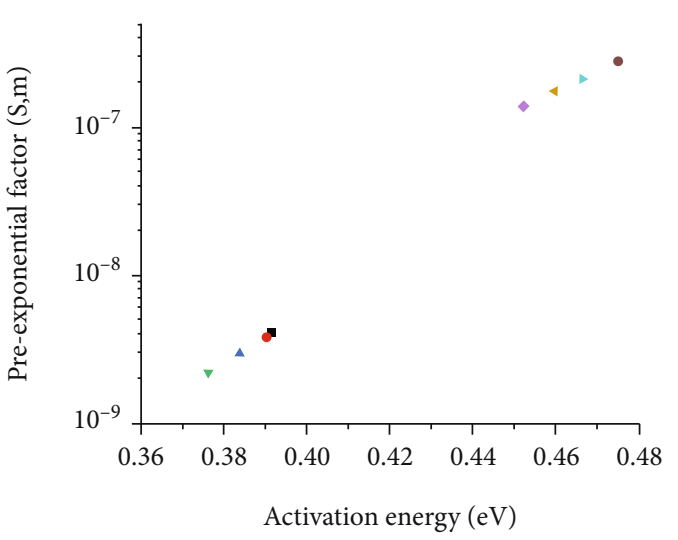

(a)

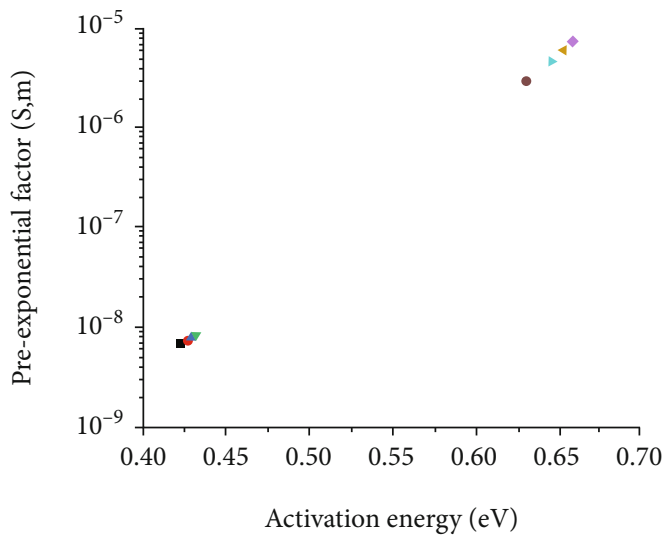

\begin{tabular}{|c|c|}
\hline Degassed sample \#1 & Degassed sample \#2 \\
\hline - $300+s$ & $300+s$ \\
\hline - $400+s$ & $400+s$ \\
\hline$\triangle 500+s$ & $500+s$ \\
\hline $600+s$ & - $600+s$ \\
\hline
\end{tabular}

(b)

FIgURe 4: Plot of activation energy and preexponential factor for (a) two degassed LDPE samples and (b) two degassed XLPE samples as a function of measurement time. The number presented in the legend is the earliest time at which the current is counted for extraction of the Arrhenius parameters.

states between samples may explain the variance in $E_{A}$. This would be independent of the choice of XLPE or LDPE. Alternatively, variation in the connectivity of the conductive interface regions could also work as an explanation $[25,26]$. Most of the difference would have to occur between samples, rather than between different types of $\mathrm{PE}$, even though they have major differences in morphology [27]. With percolative transport present, however, the average differences may not be so significant. The differences in the extremes of energy barriers would matter more. The data presented here suggests that variation in these extremes is intrinsic to polyethylene and does not appear to be significantly influenced by crosslinking. Higher activation energies in AC compared to DC conductivity also suggest that more than one physical mechanisms contribute to the compensation since for disordered materials it is more common to have lower activation energies for AC compared to DC for a single transport mechanism.

3.4. Impact of Water Exposure. To help examine the impact of water, samples of XLPE were soaked in water and then measured in AC and DC conduction modes. Rather than being degassed, the XLPE thin films were soaked in a tap water bath kept at $50^{\circ} \mathrm{C}$ for two hours. The results of the AC and DC measurements are presented in Figure 6. Figure 6(a) is the AC and DC conductivity results obtained from the water-soaked samples. Figure 6(b) is the resulting compensation plot that includes both sets of results and a comparison to the degassed XLPE samples.

Not only was an isokinetic point not observed in the water-soaked samples but compensation was also absent in AC conduction. Instead, there was a clustering of the activation energy values around $0.15 \mathrm{eV}$ and preexponential factor around $10^{-10} \mathrm{Sm}^{-1}$ in AC measurement. These samples would retain significant amounts of DCP byproducts such as acetophenone, which produces space charge in the presence of water and cumyl alochol, which would decompose into water and methylstyrene [28]. While it has been reported that water addition will enhance the conductivity and decrease the activation energy [3, 29-31] and influence the preexponential factor $[29,30]$ of polymers such as polyethylene, the presence of these chemical byproducts and their interaction with water must also be considered.

It was thus decided to clarify the matter by analyzing XLPE samples that were degassed and then soaked in tap water. These samples would still have the exposure to water, but none of the internal acetophenone or excess water from the byproducts. The samples were determined to have compensation characteristics similar to the degassed films without water soaking under both AC and DC conditions as shown in Figure 7. Parameters obtained in AC for the degassed and water-soaked samples were $97.4^{\circ} \mathrm{C}(31.9 \mathrm{meV})$ and $1.66 \times 10^{-12} \mathrm{~S} \mathrm{~m}^{-1}$, very similar to those obtained for the degassed samples and distinct from those obtained from the water-soaked, not degassed samples.

It was concluded from this study that the two hours of exposure to water did not substantially change DC conduction. Independently of degassing, the activation energy for AC conductivity in water soaked samples was greatly reduced. The initial range of activation energies was 0.3 to $1.23 \mathrm{eV}$, which decreased to 0.1 to $0.25 \mathrm{eV}$ for no degassing and 0.23 to $0.84 \mathrm{eV}$ for with degassing. Since water is primarily present in the amorphous region, the results can be interpreted that $\mathrm{AC}$ response is dominated by additives such as DCP byproducts and water while DC response is dominated by the more insulating crystaline phase. As such, the different electrical behavior of the water-soaked samples should be attributed to the combined presence of acetophenone and 


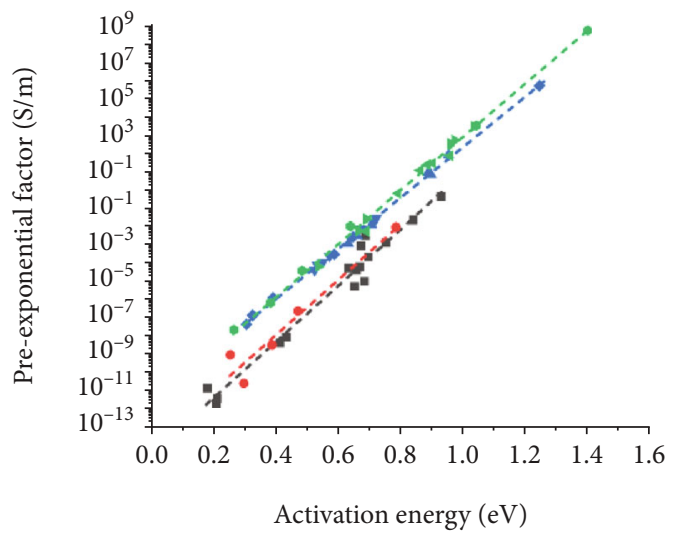

- Degassed XLPE-CCM

- - - Best fit line

- Degassed LDPE-CCM

- - - Best fit line

^ Degassed XLPE-BDS@ $0.1 \mathrm{~Hz}$

、 DegassedXLPE-BDS@1 Hz

- DegassedXLPE-BDS@10 Hz

-- - Best line

4 Degassed LDPE-BDS@ $0.1 \mathrm{~Hz}$

- Degassed LDPE-BDS@ $1 \mathrm{~Hz}$

- Degassed LDPE-BDS@ $10 \mathrm{~Hz}$

- - - Best line
Temperature $\left({ }^{\circ} \mathrm{C}\right)$

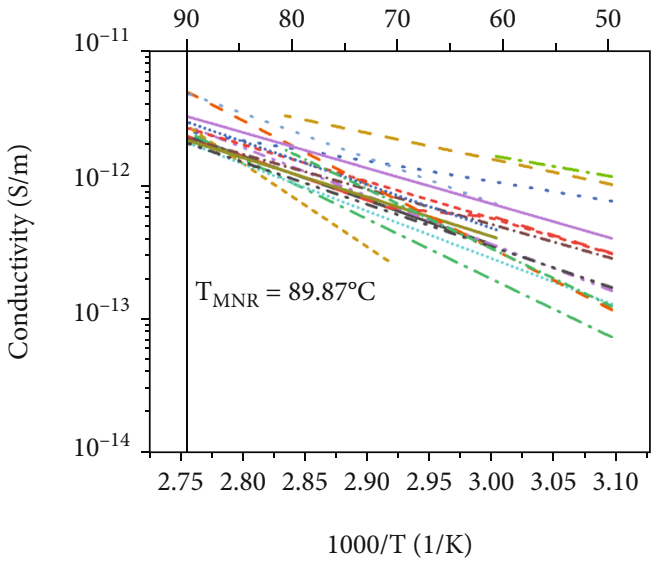

Degassed XLPE-2.3\% DCP (vacuum oven, $65^{\circ} \mathrm{C}$, 72 hours)

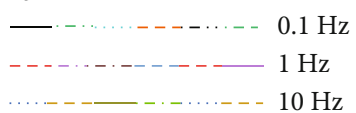

(a)

(b)

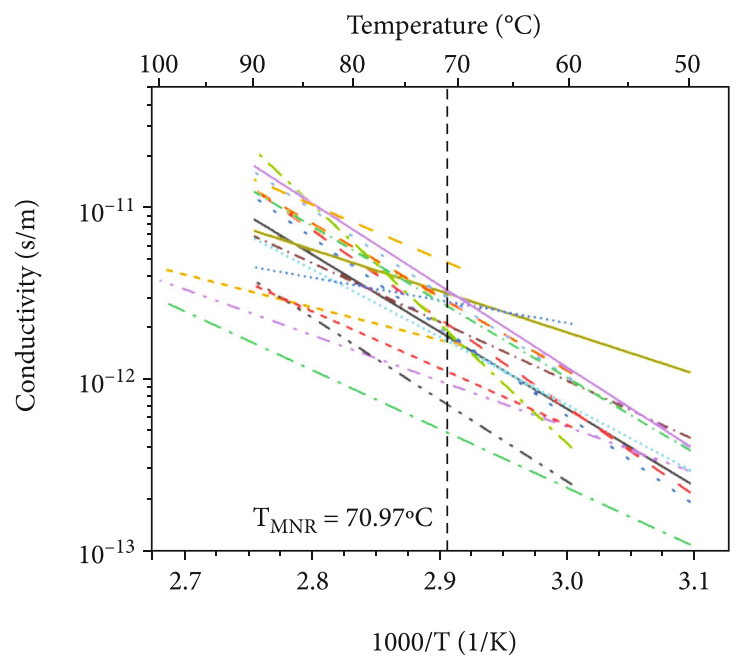

Degassed LDPE

(vacuum oven, $6501^{\circ} \mathrm{C}, 72$ hours)

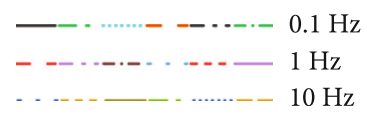

(c)

FIgURE 5: (a) Compensation law plots for degassed XLPE and degassed LDPE comparing the DC and AC results. (b, c) The corresponding conductivity vs. temperature data for the AC measurements for XLPE (b) and LDPE (c). 
TABLE 1: Comparison of Meyer-Neldel energy between degassed polyethylene samples and literature references.

\begin{tabular}{lccccc}
\hline Samples & $E_{\mathrm{MNR}}(\mathrm{meV})$ & $E_{\mathrm{MNR}} 95 \%$ confidence interval (meV) & $T_{\mathrm{MNR}}\left({ }^{\circ} \mathrm{C}\right)$ & $T_{\mathrm{MNR}}(\mathrm{K})$ & $T_{\mathrm{MNR}}$ 95\% confidence interval (K) \\
\hline d-XLPE-CCM & 28.1 & $(25.4,31.5)$ & 53 & 326 & $(295,365)$ \\
d-XLPE-BDS & 31.3 & $(30.6,32.0)$ & 90 & 363 & $(355,371)$ \\
d-LDPE-CCM & 28.6 & $(20.2,48.4)$ & 58 & 331 & $(235,562)$ \\
d-LDPE-BDS & 29.7 & $(28.7,30.7)$ & 71 & 344 & $(333,356)$ \\
LDPE [11] & - & - & 97 & 370 & - \\
$(\mathrm{PEO})_{10} \mathrm{NaI}[23]$ & - & - & 73 & 346 & - \\
$(\mathrm{PEO})_{10} \mathrm{LiClO}_{4}[23]$ & - & - & 64 & 337 & - \\
\hline
\end{tabular}

Temperature $\left({ }^{\circ} \mathrm{C}\right)$

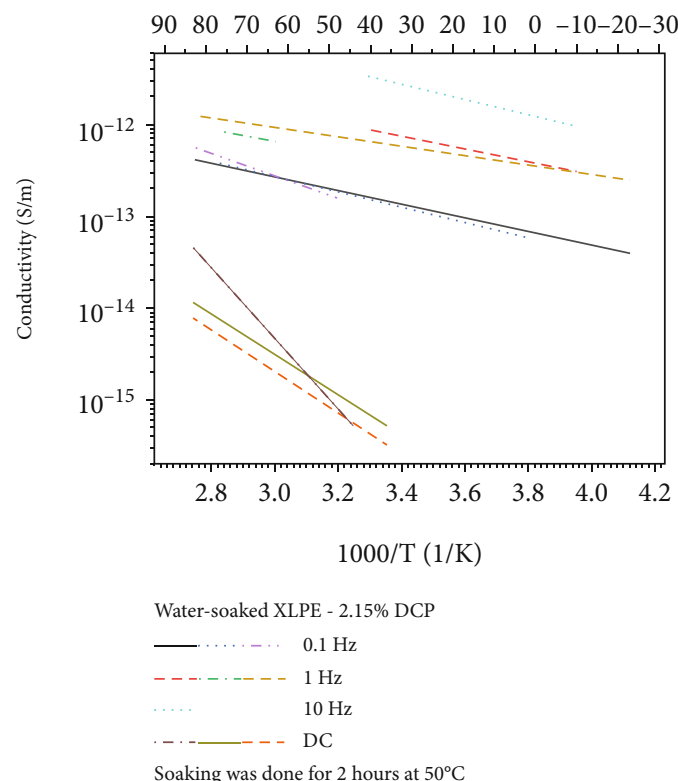

(a)
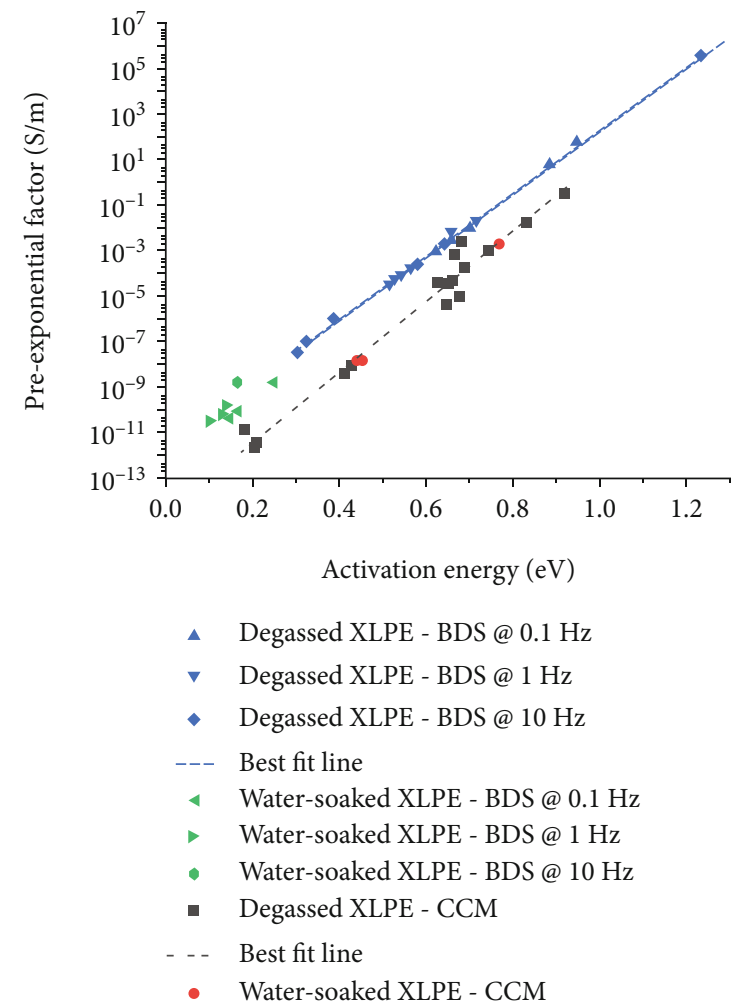

(b)

FIgure 6: (a) AC conductivity vs. temperature plot and (b) compensation law plot for water-soaked XLPE samples. A comparison to the degassed XLPE samples discussed previously is included in the plot on the right.

water inside the not-degassed XLPE. It is possible that extended water soaking to ensure the incorporation of water into the polyethylene and/or removal of byproducts could lead to a similar transition in electrical behavior, but that would need to be observed over a long time scale in a dedicated future study.

3.5. Impact of Annealing. So far, electronic transport has been assumed as the main conduction mechanism. However, water also contributes to ionic transport in polyethylene by virtue of being polarizable and ionizable. There are a number of reports of literature of hydrogen and proton contribution to compensation including the direct dependence of activation energy on proton concentration [32-34].
There is also indirect evidence for ionic transport: purifying polyethylene by removing impurities resulted in approximately two orders of magnitude reduction in leakage current [35] while a number of polymers showed a major ionic contribution to conduction from measuring the pressure dependence of electrical conductivity [36]. It is the presence of both ionic and electronic transport which can account for absence of an isokinetic point, as the two can have different points. Clearly separating ionic and electronic contributions requires a combination of simulations and experiments, and this paper summarizes initial experimental attempts to achieve this.

For example, knowing that polyethylene conductivity can be sensitive to the internal moisture content, we decided 

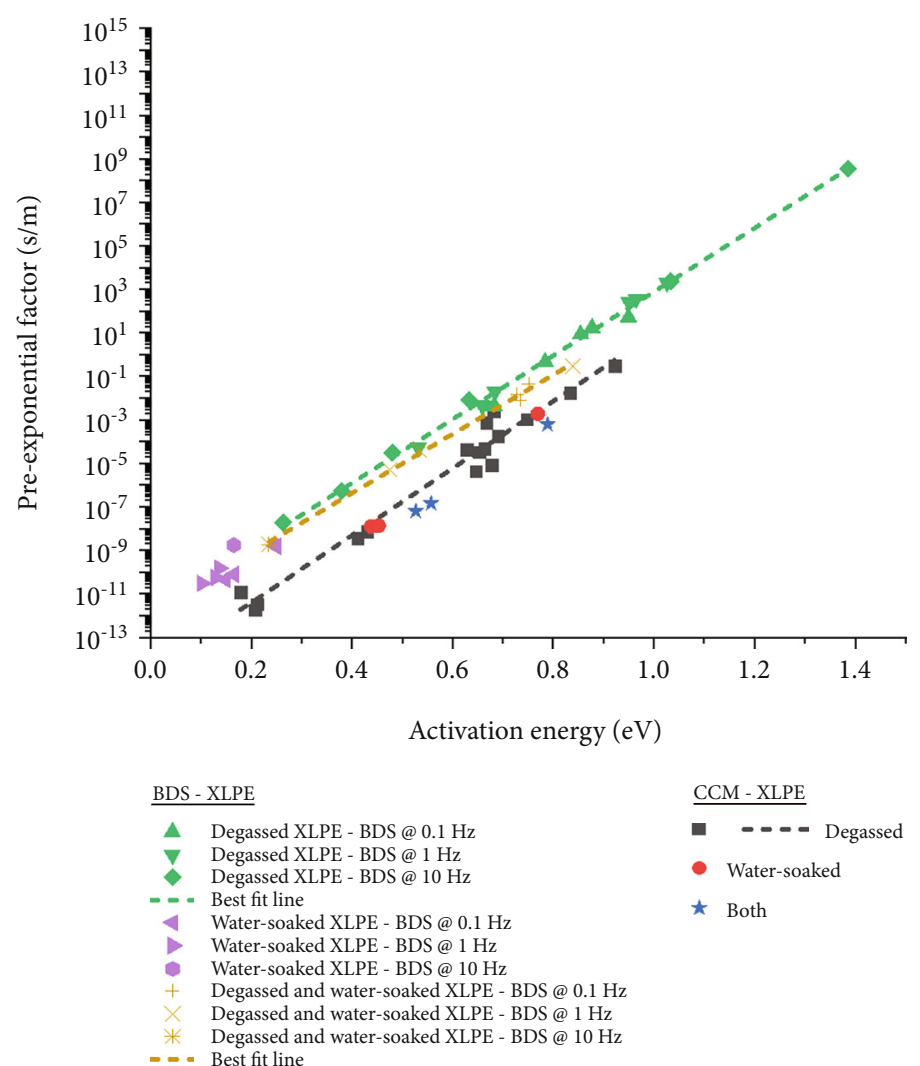

Figure 7: Compensation law plot for XLPE samples that have been both water soaked and degassed. A comparison to the XLPE samples that have been either degassed or water soaked is included in the plot.

to examine if the conductivity was also sensitive to the environment in which it was measured. Upon dehydration, it has been reported that the activation energy can be increased up to $2 \mathrm{eV}$, far in excess of the values presented earlier in this paper [31]. As such, the degassed samples likely are only partially dehydrated, due to absorbing moisture between degassing and measurement as well as having some residual trapped water. When water is absorbed by polyethylene, it is captured by a trap in the amorphous region and heavily modifies its activation energy, which is determined by the final arrangement of molecules [31].

As such, polyethylene samples were repeatedly measured under DC conditions to determine their sensitivity to humidity. These samples were only measured in DC. Three types of measurements were done: (1) the sample was measured under heating and then under cooling, (2) a heating run with no electric field applied was added prior to the cooling step, and (3) a heating and cooling run with no electric field applied was added prior to the DC measurement during heating step. The results of these experiments are shown in Figure 8. The results from the initial measurements of XLPE (Figure 8(a)) and LDPE (Figure 8(b)) are similar to those observed in Figures 1 and 2.

Unlike in many of those measurements, however, there was a region with a steep slope and a region with a shallow slope rather than having one consistent slope over the entire measurement range. Such a result has been previously observed in the literature and was attributed to an annealing effect that occurs at temperatures of $318 \mathrm{~K}\left(45^{\circ} \mathrm{C}\right)$ and above [37]. For the additional heating and cooling cycles, there were still two regions but the temperature ranges in which they were observed were flipped. The conductivity values decreased with the repeated measurements, which can indicate that water contributes to conduction. The general trend was of further reduction in conductivity as the measurements went on but with the biggest change happening between the initial heating and the initial cooling runs.

When samples were either heated from $25^{\circ} \mathrm{C}$ to $90^{\circ} \mathrm{C}$ or brought to $90^{\circ} \mathrm{C}$ and then cooled down to $25^{\circ} \mathrm{C}$ with no applied field, the next measurement run exhibited a roughly invariant conductivity at lower temperatures and then thermally activated conduction at higher temperatures as shown in Figure 8(c). This resembled the behavior of the samples in Figures 8(a) and 8(b) after the initial measurement. As such, this change can be attributed solely to the effect of heat, which is consistent with other examinations of polyethylene $[31,37,38]$. The samples had similar conductivity and activation energy values after either the initial run with voltage applied or the heat treatment without voltage. This suggests that the electrical properties of samples may equilibrate over time. In fact, measurement of one of these samples one week after ambient exposure did not lead to significant changes in the observed behavior. Whatever changes occurred in the sample due to this annealing appear to be persistent.

Using the activation energies and preexponential factors from these samples, it was decided to determine if the 


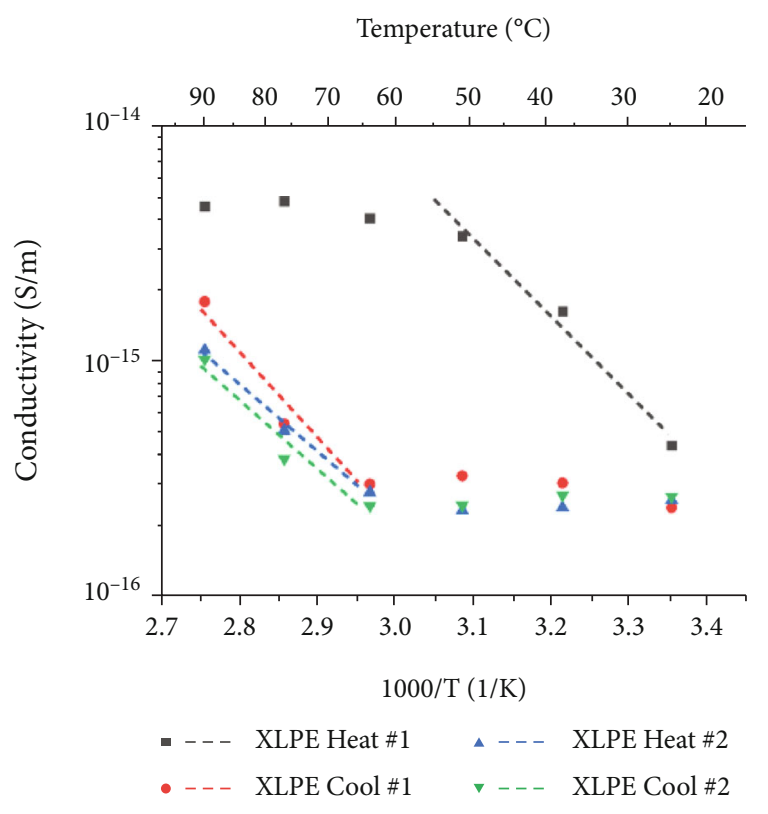

(a)

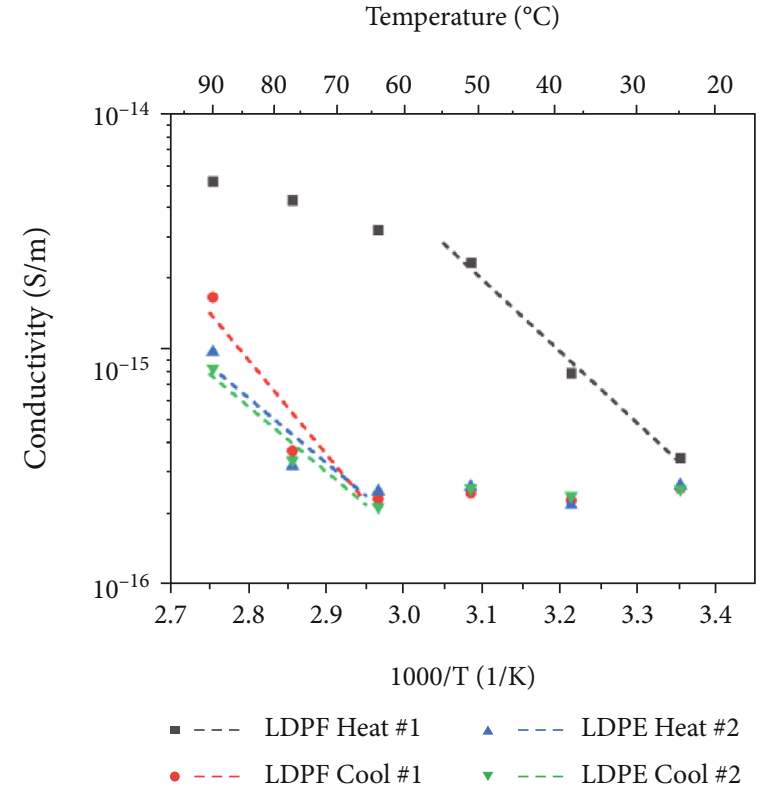

(b)

Temperature $\left({ }^{\circ} \mathrm{C}\right)$
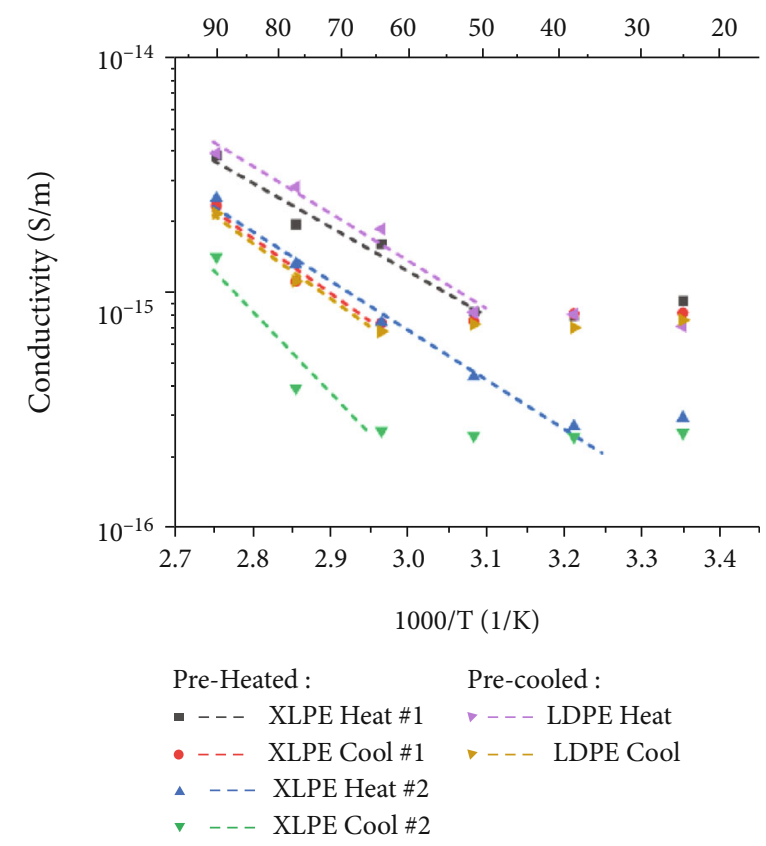

(c)

FIGURE 8: Repeated temperature-dependent conductivity measurements for degassed (a) XLPE and (b) LDPE. In part (c), the loops for $\mathrm{XLPE}$ and LDPE were preceded by either heating from $25^{\circ} \mathrm{C}$ to $90^{\circ} \mathrm{C}$ or cooling down from $90^{\circ} \mathrm{C}$ to $25^{\circ} \mathrm{C}$ the sample in the oven with no electrical field applied.

compensation law and/or an isokinetic point were present. The results are shown in Figure 9. Figure 9(a) shows the compensation behavior of two groups of XLPE and LDPE samples. The black squares are the combined XLPE and LDPE samples examined in Figures 1-3. The red circles are the combined XLPE and LDPE samples examined in Figure 8 except for the heat \#1 shown in Figures 9(a) and $9(\mathrm{~b})$.
These two groups lay upon two clearly distinct lines in Figure 9(a). As expected, there was much less variation in the samples that had been subject to the heat treatment prior to measurement, with activation energy values ranging only from $0.4 \mathrm{eV}$ to $0.8 \mathrm{eV}$. However, this was much smaller than the maximum of $2 \mathrm{eV}$ value expected if water had been completely evacuated from the samples. Furthermore, the compensation law was still applicable. Thus, 


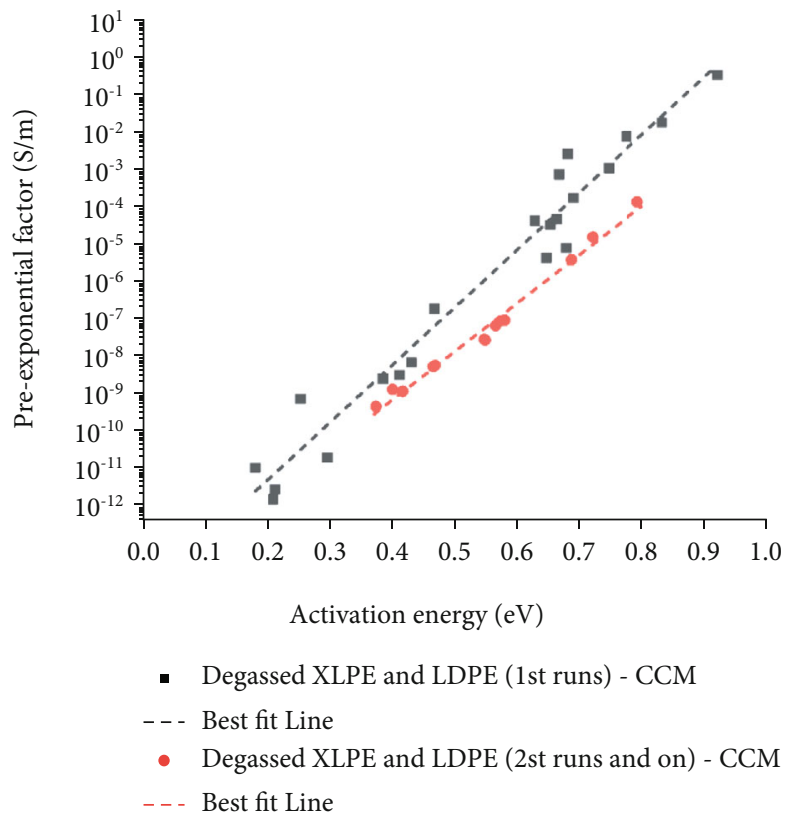

(a)

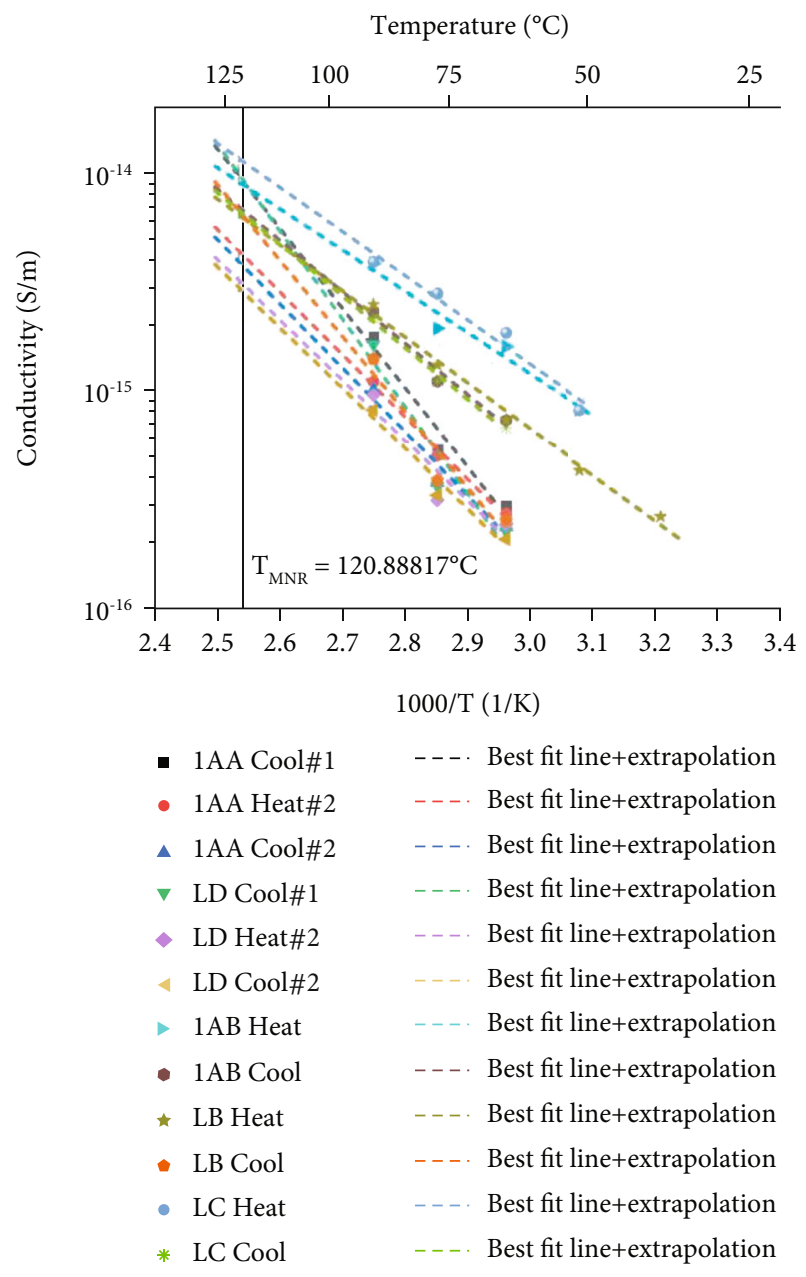

(b)

FIGURE 9: (a) Compensation plot comparing all the XLPE and LDPE samples to the runs shown in Figure 6 after initial runs or treatments. (b) Extrapolated conductivity at the nominal "isokinetic point" of $120.9^{\circ} \mathrm{C}$ for the same samples plotted in red. Legend is shown separately below the conductivity plot.

these irreversible changes should not be linked to large changes in moisture content. Instead, there are two possibilities: (1) there are some other volatile species that comes off during prolonged annealing; (2) there is an irreversible change in the structure during prolonged annealing. Given that the films are already degassed, and it is known that annealing will increase the crystallinity of polyethylene, there is more support for explanation 2 than for explanation 1. Based on the analysis of the water-soaked samples, it would make sense that if the applied heat to the sample can alter the arrangement of water and polyethylene molecules, then changes in the preexponential factor and activation energy would be observed. Such changes led to the altered compensation behavior observed in this work. This would be useful to examine via simulation, and aid in determining the impact of other molecules like DCP byproducts if a generalizable model can be developed.

The compensation parameters for the combined data in Figure $9(\mathrm{a})$ are the following: $58.3^{\circ} \mathrm{C}(28.6 \mathrm{meV})$ and 5.65 $\times 10^{-15} \mathrm{~S} \mathrm{~m}^{-1}$ for the black squares and $120.9^{\circ} \mathrm{C}(34 \mathrm{meV})$ and $6.19 \times 10^{-15} \mathrm{~S} \mathrm{~m}^{-1}$ for the red circles. This difference in Meyer-Neldel energy was confirmed to be statistically significant ( $p$ value $=0.0072$ ). Changes of this sort have been observed in other disordered materials, for example, porous silicon $[39,40]$. In those papers, it was explained that the conduction path changes from extended state transport to activated hopping. Polyethylene, in contrast, is an insulator with bandgap in excess of $8 \mathrm{eV}$ that exhibits space-charge limited current due to high concentrations of traps [41] and hopping transport through the amorphous regions that make up the bulk of the sample [42]. As such, it was concluded that this transition was due to an irreversible change in the configuration of available trap states. This thus leads to two different observed compensation behaviors and two different apparent isokinetic points.

Figure 9(b) shows the conductivity at the nominal isokinetic point of $120.9^{\circ} \mathrm{C}$ for those samples designated by red circles in Figure 9(a). Interestingly, this is close to the nominal melting point of polyethylene. Unlike in the prior cases of DC conduction, there was clustering around a conductivity value 


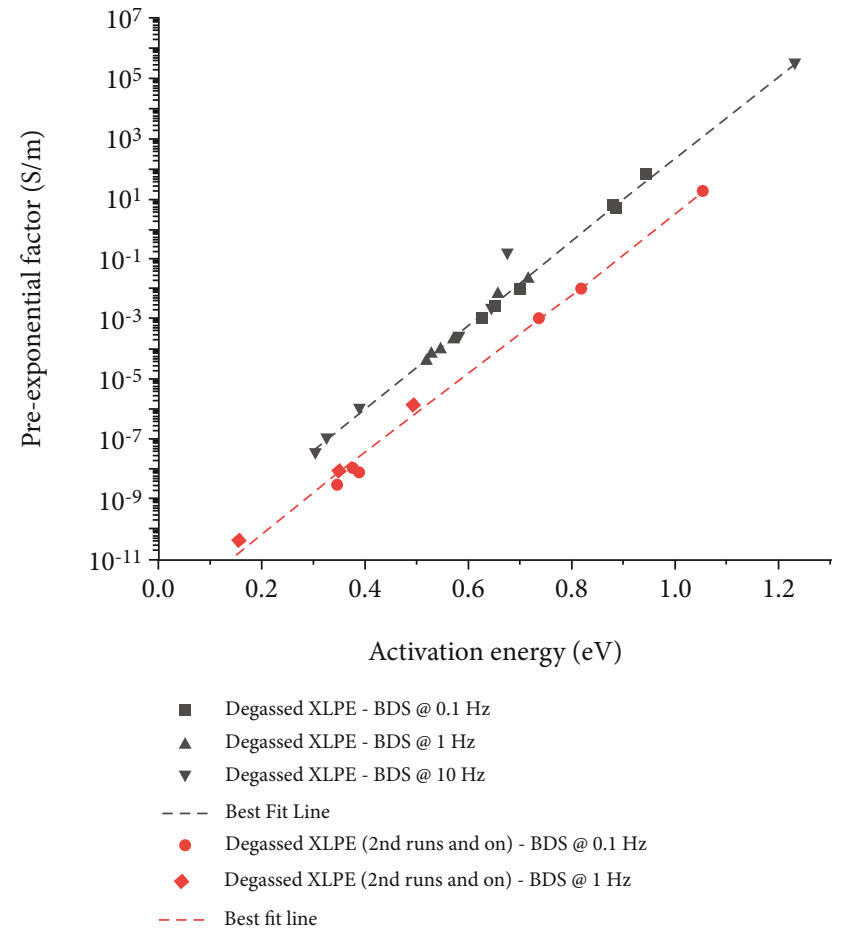

(a)
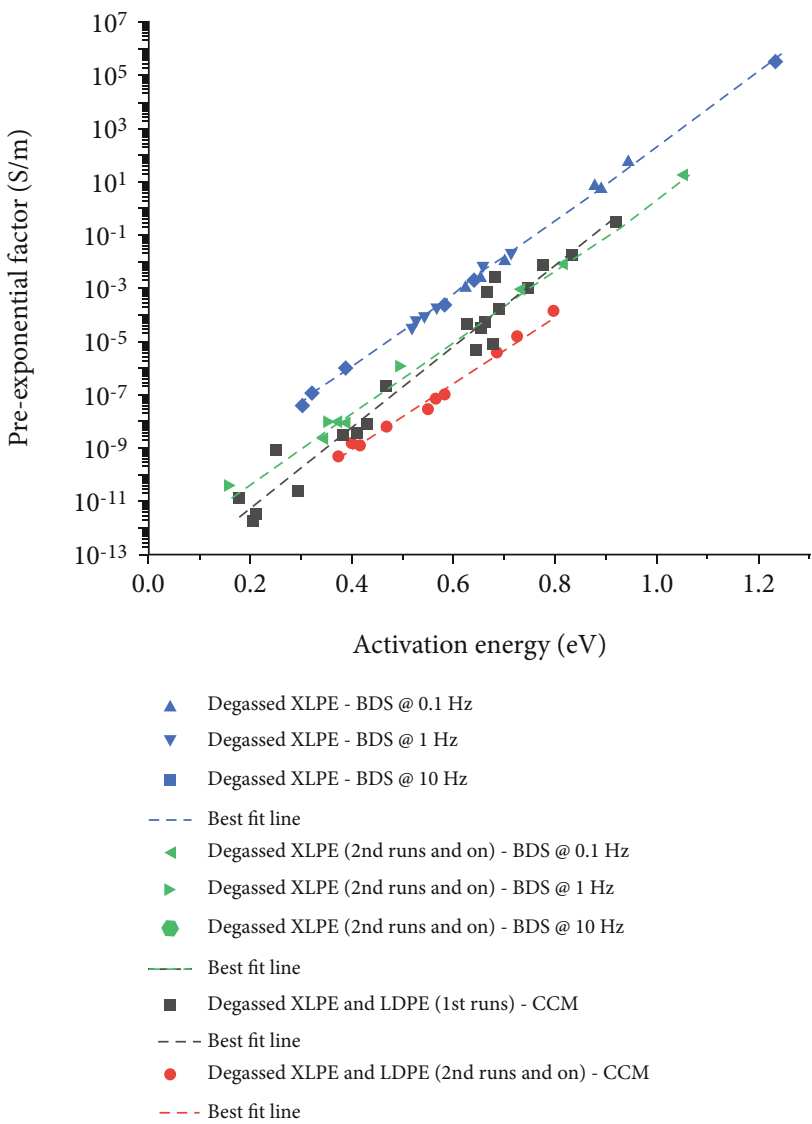

(b)

FIGURE 10: (a) Compensation plot of degassed XLPE samples repeatedly measured under AC conditions and comparison to the samples presented in Figure 4. (b) Combination of AC and DC data showing the changes in the compensation plot due to the annealing that occurs with repeat measurement or pretreatment.

of $6.29 \times 10^{-15} \pm 2.82 \times 10^{-15} \mathrm{~S} \mathrm{~m}^{-1}$. This is not a true isokinetic point since perfect overlap was not present, but a better case can be made for it here due to the irreversible changes in the polyethylene from the heat treatment. It is thus suggested that an isokinetic point may be present in polyethylene samples, but that it will be obscured by large concentrations of impurities such as water and may require heat treatment in order to appear. Alternatively, there may be two separate isokinetic points-one for ionic and one for electronic conduction. It is suggested that very long annealing times could lead to the presence of a clear isokinetic point, implying that either ionic or electronic conduction is dominant, and this would be useful to determine in future research. However, care would have to be taken to separate out aging effects. Such changes in the material are also expected to impact the electrical properties by degrading them $[3,31]$, which suggests that a combination of simulations and experiment would be required. At the same time, quantifying the impacts of aging would be useful in determining the useful lifespan of XLPE cable insulation in service.

This analysis was extended to AC measurements to determine if similar changes would be observed under those conditions. The result is shown in Figure 10, where a similar transition in the AC compensation behavior was observed, but not to the same extent as was seen in DC conditions. The compensation parameters for the combined data in Figure $10(\mathrm{a})$ are the following: $89.9^{\circ} \mathrm{C}(31.3 \mathrm{meV})$ and 2.97 $\times 10^{-12} \mathrm{~S} \mathrm{~m}^{-1}$ for the black squares and $106.2^{\circ} \mathrm{C}(32.7 \mathrm{meV})$ and $1.56 \times 10^{-13} \mathrm{~S} \mathrm{~m}^{-1}$ for the red circles. This difference could not be confirmed to be statistically significant due to an obtained $p$ value of 0.12 . However, it remained worthy of discussion. This change was deemed to have the same origin as for the change observed in the case of DC conduction: the irreversible change in the configuration of available trap states due to annealing during the initial run.

Changes in the compensation parameters of XLPE have two distinct causes: chemical from impurities and physical from annealing. The impurities from the crosslinking process had the effect of blocking compensation in the presence of water, leading to the clustering of activation energies as mentioned previously. Degassing removes these DCP byproducts from the films, but there is always some trapped water as well as water that can be added with air exposure or with intentional soaking. As such, there will be coupled ionic and electronic transport that reduces the activation energy below the expected maximum value of around $2 \mathrm{eV}$ for dried samples. It is proposed that variation in the extent of hydration between samples of the same type contributes to 
compensation effects. When samples are annealed, the coupling is retained but altered due to rearrangement of water and polyethylene molecules and loss of water. This led to the altered compensation and isokinetic behavior. Further experiments with different and harsher annealing conditions as well as simulations of electrical conduction in polyethylene as influenced by water concentration and temperature would be useful to confirm these conclusions.

\section{Conclusion}

In conclusion, LDPE and XLPE have been definitively shown to exhibit electrical compensation without a clear isokinetic point. This state of affairs exists in both DC and AC conduction and can be attributed to the wide range of activation energies available within the material $(0.2 \mathrm{eV}$ to $1.3 \mathrm{eV})$. Only the samples that were water soaked and not degassed exhibited neither compensation nor an isokinetic point, instead having to roughly constant activation energy values near $0.15 \mathrm{eV}$, though this was only under AC conditions. Rapid anneals in the oven altered the compensation behavior, but did not lead to the emergence of an isokinetic point. A summary table of the resulting activation energies and Meyer-Neldel temperatures for each type of sample and measurement is presented in Table S1.

The absence of a clear isokinetic point, despite the presence of compensation, is attributed to three factors. First, the arrangement of traps and water molecules, which can alter the trap energy, varies on a sample-to-sample basis. Second, two contributions to conduction exist in polyethylene-electronic and ionic-and the two can have their own isokinetic point and contribute differently in the amorphous and crystalline portions of semicrystalline polymer. Third, both dispersive transport and dielectrophoretic behavior exist within polyethylene, which creates alternative conductive pathways. These factors combine to make variation in conduction from sample to sample, even when they should be similar, an experimental certainty.

Given this complexity, further work examining the electrical conductivity of polyethylene at long timescales and with stronger annealing conditions using a combination of simulations and experiments is suggested. It is necessary to better understand this material, its properties, and its longevity given its wide use in power cables. Furthermore, it is suggested to combine electrical measurements with measurements of sample hydration before and after each measurement, to verify if moisture content changes during AC or DC measurements, and to examine how the distribution of water molecules may change. During those experiments, the impact of doing DC measurement prior to AC measurement can also be examined to see if the order in which characterization is done matters.

\section{Data Availability}

The data that support the findings of this study are available from the corresponding author upon reasonable request.

\section{Conflicts of Interest}

The authors declare that they have no conflicts of interest.

\section{Acknowledgments}

This research was funded by Dow under University Partnership Initiative 225559AM. We also thank the Penn State Electrical Characterization Laboratory staff for their assistance.

\section{Supplementary Materials}

One additional figure and table can be found in the Supplemental Information file. Figure S1 shows schematic conductivity data. Table S1 is a summary of the measured range of activation energies and Meyer-Neldel temperature for each sample type. (Supplementary Materials)

\section{References}

[1] W. Meyer and H. Neldel, "Über die Beziehungen," Zeitschrift für Technische Physik, vol. 18, pp. 588-593, 1937.

[2] A. Yelon, B. Movaghar, and H. M. Branz, "Origin and consequences of the compensation (Meyer-Neldel) law," Physical Review B, vol. 46, no. 19, pp. 12244-12250, 1992.

[3] J. C. Palacios, M. G. Olayo, G. J. Cruz, J. A. Chávez-Carvayar, and J. Open, "Meyer-Neldel Rule in Plasma Polythiophene Thin Films," Polymer Chemistry, vol. 4, no. 3, pp. 31-37, 2014.

[4] A. Yildiz, F. Iacomi, M. Cazacu, A. Amironesei, G. I. Rusu, and S. Simon, "The Meyer-Neldel rule in layered silicone-silver nanocomposites," Polymer Composites, vol. 32, no. 11, pp. 1751-1756, 2011.

[5] A. Yelon and B. Movaghar, "Microscopic explanation of the compensation (Meyer-Neldel) rule," Physical Review Letters, vol. 65, no. 5, pp. 618-620, 1990.

[6] G. Boisvert, L. J. Lewis, and A. Yelon, "Many-Body Nature of the Meyer-Neldel Compensation Law for Diffusion," Physical Review Letters, vol. 75, no. 3, pp. 469-472, 1995.

[7] L. Liu and Q.-X. Guo, "Isokinetic Relationship, Isoequilibrium Relationship, and Enthalpy-Entropy Compensation," Chemical Reviews, vol. 101, no. 3, pp. 673-696, 2001.

[8] R. C. Petersen, "The Linear Relationship between Enthalpy and Entropy of Activation," The Journal of Organic Chemistry, vol. 29, no. 11, pp. 3133-3135, 1964.

[9] M. P. Suárez, A. Palermo, and C. M. J. Aldao, "The compensation effect revisited," Journal of Thermal Analysis, vol. 41, no. 4, pp. 807-816, 1994.

[10] Z. Karpinski and R. Larsson, "On the Isokinetic Effect of Neopentane Hydrogenolysis over Metal Catalysts," Journal of Catalysis, vol. 168, no. 2, pp. 532-537, 1997.

[11] G. Sawa, M. Ieda, and K. Kitagawa, "Relation between preexponential factor and activation energy in dark conductivity of polyethylene," Electronics Letters, vol. 10, no. 5, p. 50, 1974.

[12] M. Masui, H. Nagasaka, and K. Yahagi, "Pre-Exponential Factor in Electrical Conductivity of Uniaxially Drawn Low Density Polyethylene," Japanese Journal of Applied Physics, vol. 16, no. 1, pp. 177-178, 1977. 
[13] T. J. HAMMONS, "Power Cables in the Twenty-First Century," Electric Power Components and Systems, vol. 31, no. 10, pp. 967-994, 2003.

[14] T. Andrews, R. N. Hampton, A. Smedberg, D. Wald, V. Waschk, and W. Weissenberg, "The role of degassing in XLPE power cable manufacture," IEEE Electrical Insulation Magazine, vol. 22, no. 6, pp. 5-16, 2006.

[15] L. Boudou and J. J. Guastavino, "Influence of temperature on low-density polyethylene films through conduction measurement," Journal of Physics D: Applied Physics, vol. 35, no. 13, pp. 1555-1561, 2002.

[16] G. C. Montanari, G. Mazzanti, F. Palmieri, A. Motori, G. Perego, and S. J. Serra, "Space-charge trapping and conduction in LDPE, HDPE and XLPE," Journal of Physics D: Applied Physics, vol. 34, no. 18, pp. 2902-2911, 2001.

[17] R. K. Jackson, O. C. Onar, H. Kirkham et al., Opportunities for efficiency improvements in the U.S, Electricity Transmission and Distribution System, Oak Ridge, TN (United States), 2015.

[18] P. J. Barrie, "The mathematical origins of the kinetic compensation effect: 1. the effect of random experimental errors," Physical Chemistry Chemical Physics, vol. 14, no. 1, pp. 318326, 2012.

[19] P. J. Barrie, "The mathematical origins of the kinetic compensation effect: 2 . the effect of systematic errors," Physical Chemistry Chemical Physics, vol. 14, no. 1, pp. 327-336, 2012.

[20] A. Yelon, E. Sacher, and W. Linert, "Comment on "The mathematical origins of the kinetic compensation effect" Parts 1 and 2 by P. J. Barrie, Phys. Chem. Chem. Phys., 2012, 14, 318 and 327," Physical Chemistry Chemical Physics, vol. 14, no. 22, p. 8232, 2012.

[21] T. Tiedje and A. Rose, "A physical interpretation of dispersive transport in disordered semiconductors," Solid State Communications, vol. 37, no. 1, pp. 49-52, 1981.

[22] W. B. Jackson, "Connection between the Meyer-Neldel relation and multiple-trapping transport," Physical Review B, vol. 38, no. 5, pp. 3595-3598, 1988.

[23] L. Chen, T. D. Huan, and R. Ramprasad, "Electronic Structure of Polyethylene: Role of Chemical, Morphological and Interfacial Complexity," Scientific Reports, vol. 7, no. 1, pp. 1-10, 2017.

[24] W. Wieczorek and M. Siekierski, "A description of the temperature dependence of the conductivity for composite polymeric electrolytes by effective medium theory," Journal of Applied Physics, vol. 76, no. 4, pp. 2220-2226, 1994.

[25] M. Unge, T. Christen, and C. Tornkvist, "Electronic structure of polyethylene-Crystalline and amorphous phases of pure polyethylene and their interfaces," in In 2012 Annual Report Conference on Electrical Insulation and Dielectric Phenomena IEEE, pp. 525-530, 2012.

[26] S. Nilsson, T. Hjertberg, and A. Smedberg, "Structural effects on thermal properties and morphology in XLPE," European Polymer Journal, vol. 46, no. 8, pp. 1759-1769, 2010.

[27] W. Wieczorek, "Temperature dependence of conductivity of mixed-phase composite polymer solid electrolytes," Materials Science and Engineering B, vol. 15, no. 2, pp. 108-114, 1992.

[28] R. C. Walker, H. Hamedi, W. H. Woodward, and M. Lanagan, "Thermally stimulated depolarization current spectra of crosslinked polyethylene and the influence of cross-linking byproducts," Journal of Polymer Science, vol. 58, no. 22, pp. 3142$3152,2020$.
[29] B. Rosenberg, B. B. Bhowmik, H. C. Harder, and E. Postow, "Pre-exponential Factor in Semiconducting Organic Substances," The Journal of Chemical Physics, vol. 49, no. 9, pp. 4108-4114, 1968.

[30] D. D. Eley, A. S. Fawcett, and M. R. Willis, "Semiconductivity of organic substances. Part 12.-Electrode injection of charge carriers into crystals of small aromatic molecules," In Transactions of the Faraday Society, vol. 64, pp. 1513-1527, 1968.

[31] C. G. Garton and N. Parkman, "Experimental and theoretical investigation of conduction in polyethylene from $4 \mathrm{MV} / \mathrm{m}$ up to 'intrinsic' breakdown," Proceedings of the Institution of Electrical Engineers, vol. 123, no. 3, pp. 271-276, 1976.

[32] A. G. Jones, "Compensation of the Meyer-Neldel Compensation Law for $\mathrm{H}$ diffusion in minerals," Geochemistry, Geophysics, Geosystems, vol. 15, no. 6, pp. 2616-2631, 2014.

[33] A. Yelon, "High and low activation energy kinetics are different: Implications for hydrogen and protons in condensed matter," MRS Advances, vol. 2, no. 7, pp. 425-429, 2017.

[34] J. Shinar, R. Shinar, X. L. Wu, S. Mitra, and F. R. Girvan, "Hydrogen dynamics in a-Si:H: Multiple trapping, structural relaxation, and the Meyer-Neldel relation," Physical Review $B$, vol. 43, no. 2, pp. 1631-1636, 1991.

[35] R. H. J. Partridge, "The extrinsic nature of electrical conductivity in polyethylene," Journal of Polymer Science Part B: Polymer Letters, vol. 5, no. 2, pp. 205-208, 1967.

[36] S. Saito, H. Sasabe, T. Nakajima, and K. Yada, "Dielectric relaxation and electrical conduction of polymers as a function of pressure and temperature," Journal of Polymer Science Part A-2: Polymer Physics, vol. 6, no. 7, pp. 1297-1315, 1968.

[37] L. Boudou and J. J. Guastavino, "Influence of temperature treatment on the electrical properties of low-density polyethylene," Journal of Physics D: Applied Physics, vol. 33, no. 21, pp. L129-L131, 2000.

[38] G. Sawa, K. Kitagawa, and M. Ieda, "Pre-Exponential Factor in Electrical Conductivity of Irradiated Polyethylene," Japanese Journal of Applied Physics, vol. 11, no. 3, pp. 416B-4417, 1972.

[39] Y. Lubianiker and I. Balberg, "Two Meyer-Neldel Rules in Porous Silicon," Physical Review Letters, vol. 78, no. 12, pp. 2433-2436, 1997.

[40] Y. Lubianiker and I. J. Balberg, "A comparative study of the Meyer-Neldel rule in porous silicon and hydrogenated amorphous silicon," Non-Crystalline Solids, vol. 227-230, pp. 180184, 1998.

[41] L. Lan, J. Wu, Y. Yin, X. Li, and Z. Li, "Effect of temperature on space charge trapping and conduction in cross-linked polyethylene," IEEE Transactions on Dielectrics and Electrical Insulation, vol. 21, no. 4, pp. 1784-1791, 2014.

[42] R. J. Fleming and J. Brazilian, "Space charge in polymers, particularly polyethylene," Physiologie, vol. 29, no. 2, pp. 280-294, 1999. 